\title{
Crowding in Germany's national parks: the case of the low mountain range Saxon Switzerland National Park
}

\author{
Johannes Schamel \& Hubert Job
}

Keywords: visitor management, social carrying capacity, crowding, displacement, national park

\section{Abstract}

Every year 1.7 million people visit the Saxon Switzerland National Park, resulting in a very high visitor density, especially in the western parts of the national park. This pathe perception of crowding, influencing factors and displacement effects. Overall, nearly one third of the visitors (31.3\%) felt crowded, with a maximum of $74.4 \%$ at the Bastei rock, a popular spot within the park. Using a logistic regression, the number of perceived encounters, plus motives and expectations were found to be the key factors to influence the perception of crowding. Nearly half of the visitors (48.7\%) already act or plan to act on crowding, choosing temporal and spatial displacement strategies in equal measure. per presents the results of a survey conducted in 2011 ( $n=312)$, which investigated

Profile

Protected area

Saxon Switzerland National Park

Mountain range

Elbe Sandstone mountains

Country

Germany

\section{Introduction}

Visitor management and social carrying capacity in Saxon Switzerland National Park (NP)

In the rocky cliffs and narrow canyons of the low mountain range of Saxon Switzerland, rock climbing in its modern form had first emerged in the second half of the $19^{\text {th }}$ century. Shortly after, when the ecological consequences of this new activity became obvious, the first summits were closed for climbing. This early form of visitor management gradually developed into a visitor management plan of the NP, which was founded in 1990 and consists of two separate areas (Figure 2). The management plan defines a core zone, in which stricter regulations, for example, the obligation to stick to marked trails, are in force (Staatsbetrieb Sachsenforst). These regulations are formulated with a primary focus on the ecological impact of outdoor recreation, but not on social impacts like crowding.

This is a common situation in European NP management and research, even though new topics like human wellbeing have gained in significance in recent years (Hammer et al. 2012). In Germany, for example, few studies are addressing social carrying capacity and crowding (Grossmann et al. 2004; Kalisch \& Klaphake 2007; Kalisch 2012; Volz \& Mann 2007). Only one of them was conducted in a low mountain range and none of them included a nation-wide known visitor attraction and visitor hotspot, where displacement effects are likely to occur. In the national park system of Germany, few attractions are so popular: the Brocken summit in Harz NP, lake Königssee in Berchtesgaden NP and the Königsstuhl cliffs in Jasmund NP. The fourth attraction that can be classified as a nationwide known attraction is the Bastei rock investigated in this study. More than half of the 1.7 million annual visitors (of which 900000 stay overnight) who come

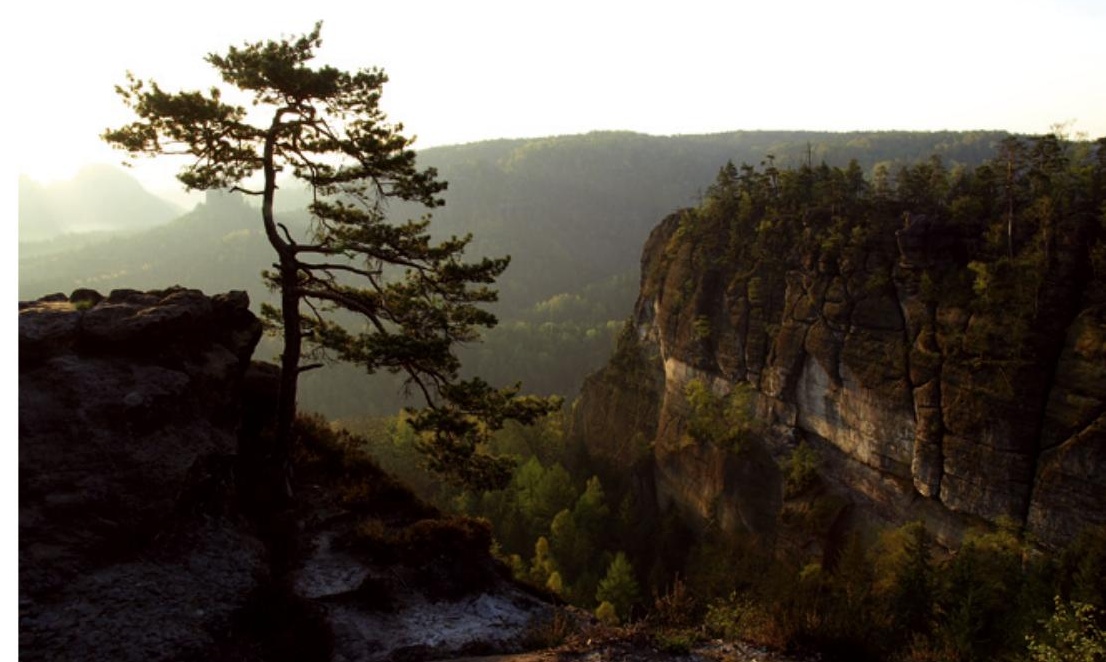

Figure 1 - Saxon Switzerland NP. (C) Holm Riebe

to Saxon Switzerland NP visit the Bastei (Job et al. 2010). This means that the high average visitor density of about 183 visitors per hectare (Mayer et al. 2010) for the whole NP is substantially driven by the visitor numbers in this spot. Given these numbers and results of Schreiner (2009), who found slight to medium levels of crowding in the eastern part of the NP, social conflicts seem very likely in the western part of the NP and especially at the Bastei rock.

\section{State of the art}

Crowding, which can be defined as "a negative evaluation of the number of people the individual remembers seeing" (Vaske \& Donellly 2002), has a long research tradition in North America. Numerous factors have been found to influence crowding perception (Trachsel \& Backhaus 2011; Sterl et al. 2004; Noe et al. 1997; Vaske \& Donnelly 2002; Webb \& Worchel 1993; Absher \& Lee 1981; Kalisch 2012; Andereck \& Becker 1993). 


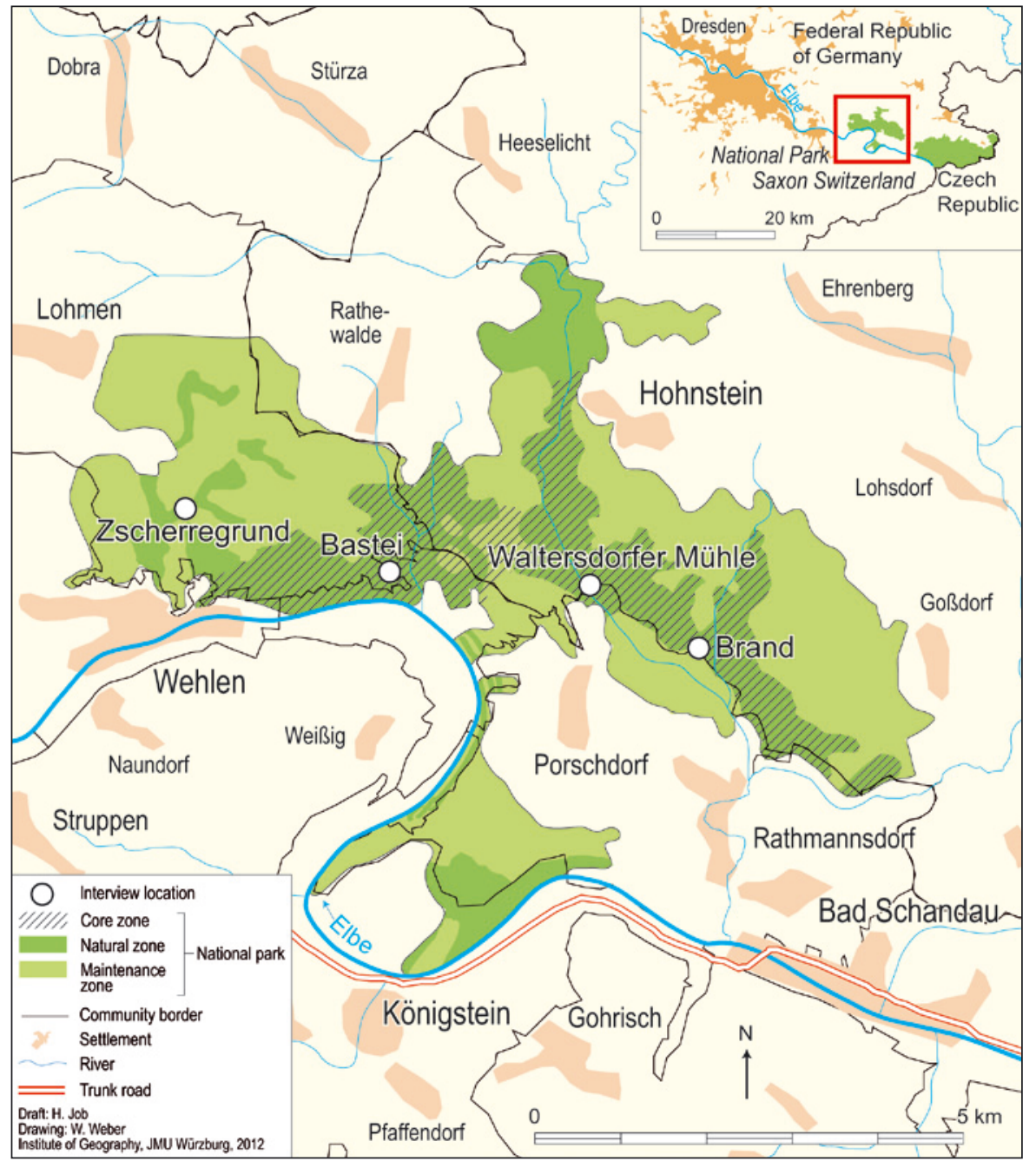

Figure 2 - Map of the western part of Saxon Switzerland NP

These factors can be grouped into three main categories (Figure 3): visitor characteristics, characteristics of those encountered and situational variables. Visitor characteristics primarily include the motivation for the visit, expectations of use levels, preferences for contacts and the level of visitors' familiarity with the area. Visitors seeking solitude (Ditton et al. 1983), expecting and preferring few encounters (Shelby 1980; Kernen et al. 2010) and experienced visitors (Arnberger \& Brandenburg 2007) were found to be more sensitive to crowding. The characteristics of those encountered, like their group size or their behaviour (Manning 2011; Arnberger \& Haider 2005) were also found to be important. Carothers et al. (2001) noted that hikers are much more disturbed by mountain bikers than the other way round. Finally, situational variables like the area type, from wilderness conditions to highly developed infrastructure in a NP, or the time and season of the visit can also influence the perception of crowding.

Some, but not all, visitors chose a coping strategy as a reaction to crowding. Especially when crowding perception is low, some visitors do not react. Those reacting to crowding adopt one of two major coping strategies: cognitive mechanisms and displacement. Cognitive mechanisms include product shift and ra- tionalization. Both strategies weaken the relationship between usage levels and satisfaction (Kuentzel \& Heberlein 1992; Shelby \& Heberlein 1986; Manning \& Valliere 2001).

Displacement, the second major coping strategy for crowding, can take different forms: spatial, temporal and usage displacement. Visitors can displace spatially, either by visiting a less frequented area of the park (intra-area displacement) or by visiting another recreational area (inter-area displacement). Temporal displacement can occur as a daytime, weekday or seasonal shift of usage. Usage displacement takes the form of changing the activity but staying in the same area (Shelby \& Vaske 1991; Arnberger \& Brandenburg 2007).

Although the choice of a specific form of displacement depends on the attachment to the place, other factors, such as availability of alternate sites and logistic constraints were also found to be important (Kuentzel \& Heberlein 1992; Hall \& Shelby 2000; Arnberger \& Brandenburg 2007). Visitors who are very attached to a specific area are more likely to prefer temporal adjustments than displacing spatially, whereas inter-area displacement is often applied if many alternative recreation areas exist (Arnberger \& Brandenburg 2007). 


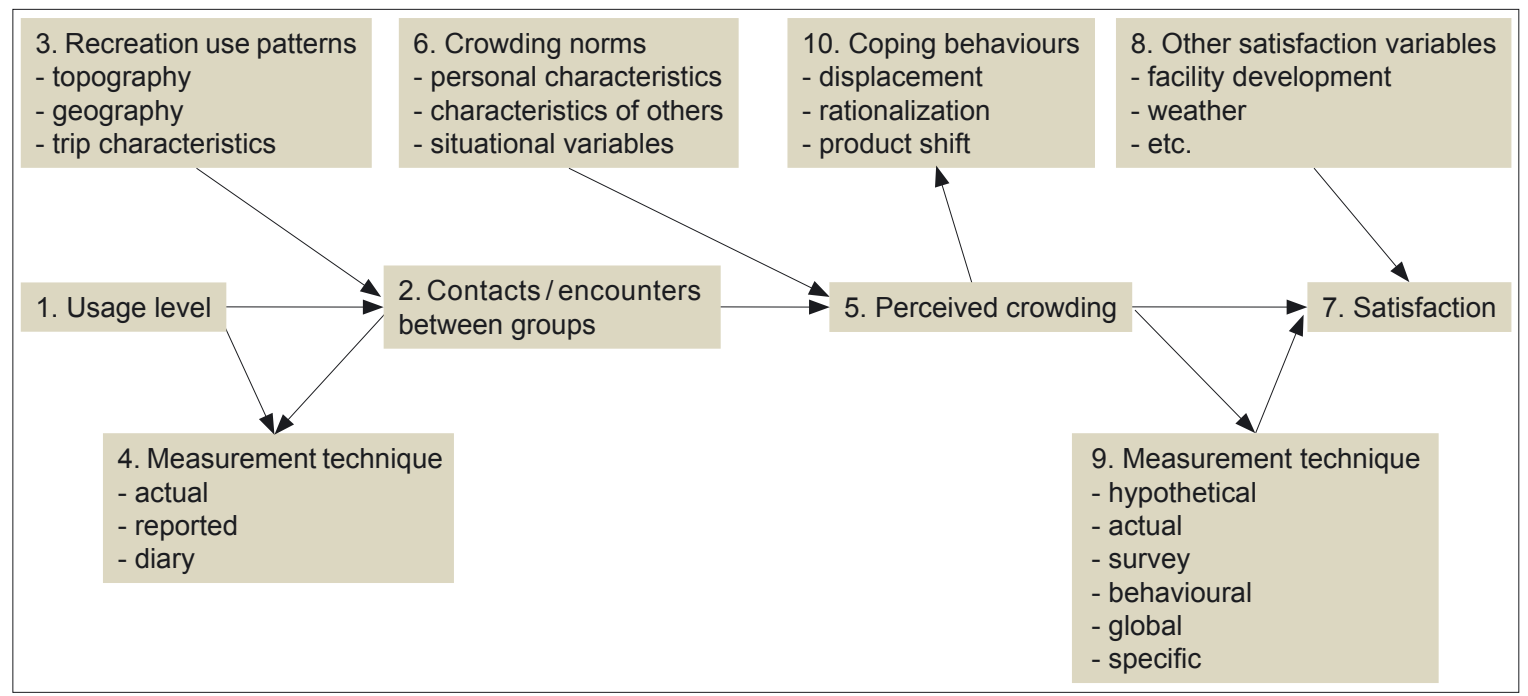

Figure 3 - Expanded crowding model (Source: modified after Manning 2011, p. 110)

Although crowding was found to be a major reason for displacement, other social factors also come into play (Arnberger \& Haider 2007).

\section{Study objectives}

Given the very limited literature on the comparatively young national parks in Germany (Job 2010), the aim of this paper is to provide insights into the different aspects of crowding, with a special focus on the Bastei, a nation-wide known visitor attraction. Therefore, crowding perception and its intra-area differences should be investigated. A second objective is to analyse the factors which influence the crowding perception in a high-use, low-mountain range. This is essential for proposing adequate management measures, which effectively address crowding. Finally coping mechanisms in response to crowding are investigated.

\section{Methods}

\section{Data sampling}

Data were collected on five days from Wednesday to Sunday at the end of April and the beginning of May 2011, from 9 am to 5 pm every day. The study can thus be seen as representative for the two peak seasons spring and autumn, which attain equal visitor numbers (Job et al. 2010). The four interviewer locations were chosen in consultation with the management of the NP to be representative for the western part of the park. The Bastei and Brand rocks are both gathering points, easily accessible within a short hike without significant elevation gain, and attain moderate to high visitor numbers. Near the Waltersdorfer Mühle inn and the Zescherregrund ravine, interviewers were placed at trails in less frequented areas which can only be reached by a moderate hike. Every visitor encountered was asked to participate in the study as long as no interview was already underway. In total 312 persons were interviewed.

\section{Crowding measurement}

A standardized questionnaire was used and the questions can be grouped in three categories. First, personal characteristics of the visitor, e. g. socio-demographic data, motives for visiting the NP, mode of travel and familiarity with the NP area. Second, encounters: visitors were asked to state the number of encounters, the number of expected encounters and the behaviour of the encountered persons. The first two questions were supported by digitally calibrated images. Especially in high density settings, this visual support has proved to enhance the validity of responses compared to strictly numerically approaches as it reduces the abstraction effort needed to express a visual experience as a numerical value (Manning \& Freimund 2004; Hall \& Roggenbruck 2002). Six digitally manipulated images (Figure 4) were handed out to the visitors, each showing the same trail. The characteristics of the trail and the depicted natural setting (rock formations, coniferous forest) were typical for most trails in the western part of Saxon Switzerland NP. People were placed in twos, equally distributed across fore- and background.

The last category of the questions examined crowding perception and displacement effects. Crowding perception is measured by a verbal approach, using the 9-point-Likert scale of Heberlein \& Vaske (1977). This approach has been applied in a vast number of studies worldwide (Vaske \& Shelby 2008).

\section{Data aggregation and analysis}

For further analysis, using logistic regression modeling, the data were recoded and aggregated. The 9-point crowding-scale is aggregated to a dichotomous variable, using a breaking point between 4 (slightly crowded) and 5 (moderately crowded). This distinction was suggested by Shelby \& Vaske (2008) for frontcountry settings of NPs. A logistic regression analysis was applied to determine the influencing factors on crowding. The logistic regression allows quantifying the individual influence of each independent 

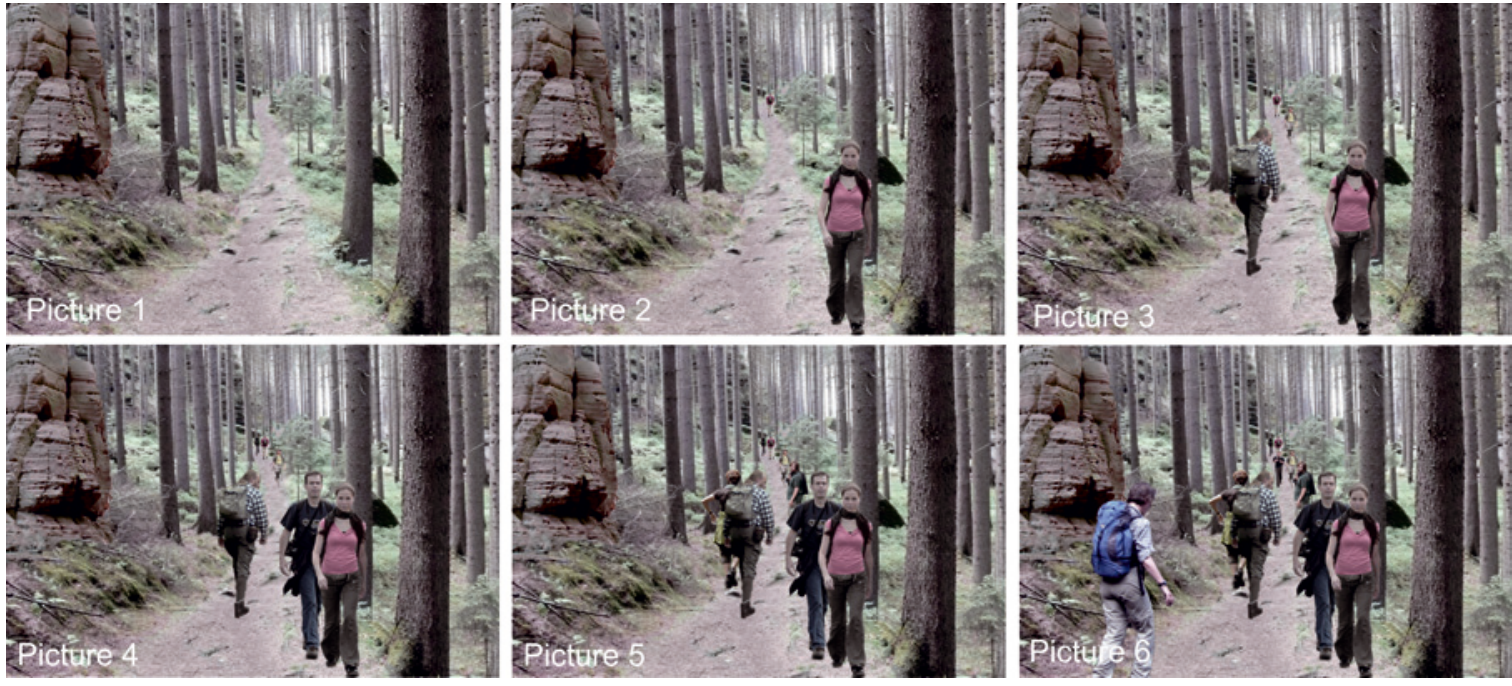

Figure 3 - Series of photographs handed out to visitors

variable on the dependent variable, in this case the dichotomous crowding variable.

\section{Results}

\section{Crowding perception}

The overall mean of 3.83 suggests that only slight forms of crowding occur in the NP, however significant intra-area differences exist (Table 1). The highest mean was found at the Bastei rock (5.76), where nearly three out of four visitors reported feeling at least moderately crowded. In contrast, at the locations along trails to Zescherregrund ravine and Waltersdorfer Mühle inn, the level of crowding-perception remains low with means of 3.03 and 2.73 .

A logistic regression model was used to determine the influencing factors on crowding. After eliminating outliers (cases with a standardized z-residual $>4$ ) and missing values, 277 cases remained in the analysis. The model fit seems satisfactory. $83.8 \%$ of the cases were classified correctly and the Nagelkerke- $\mathrm{R}^{2}$ returned a value of 0.58 (Table 2). Crowding perception depended primarily on the number of encounters. A moderate number of encounters increased the likelihood to report crowding by a factor of 21.9 ( $p<0.01)$, compared to a situation with few encounters. If many visitors were encountered, the factor was even higher $(\operatorname{Exp}(\beta)=146.1, p<0.01)$. The bivariate correlation confirms the high influence of the number of encounters with a Spearman-Rho of $0.67(\mathrm{p}<0.01)$. However, at the Bastei rock the correlation between perceived encounters and perceived crowding is much lower, with a value of $0.31(\mathrm{p}<0.01)$.

Only two other variables were significant besides the visitor encounters: the category recreation of the motivation variable and the category other of the activity variable. However, the latter cannot be interpreted meaningfully due to a low sample size and a heterogeneous composition. The former returned an effect coefficient of $\operatorname{Exp}(\beta)=0.198$. Thus the likelihood to
Table $1-$ Crowding perception per interview location $(n=309)$

\begin{tabular}{|l|r|r|r|r|}
\hline & \multicolumn{1}{|c|}{ N } & Mean & SD & $\begin{array}{c}\text { Crowding } \\
\text { perception } \geq 5\end{array}$ \\
\hline Bastei & 85 & 5.76 & 1.68 & $74.4 \%$ \\
\hline Brand & 75 & 3.51 & 1.52 & $25.3 \%$ \\
\hline Zescherregrund & 74 & 3.03 & 1.49 & $8.0 \%$ \\
\hline Waltersdorfer Mühle & 75 & 2.73 & 1.07 & $12.0 \%$ \\
\hline Total & 309 & 3.83 & 1.91 & $31.4 \%$ \\
\hline
\end{tabular}

report crowding is about five times lower if the primary motive for the visit was recreation and not experiencing nature. The same tendency could be observed when the motives of nature experience and activity with family and friends $(\operatorname{Exp}(\beta)=0.61)$ are compared, however not on a significant level $(p=0.29)$.

The variable expectations was disaggregated for further investigation. The group of visitors who felt crowded significantly underestimated the usage levels more often than the visitors who didn't feel crowded $(p<0.01$, Mann-Whitney-U-test). Table 3 illustrates that in the two new categories heavily underestimated and beavily overestimated the distribution is distinct.

\section{Displacement effects and coping strategies}

Of the 312 respondents, $51 \%$ didn't react or plan to react on crowding (Table 4). The remaining 152 respondents applied spatial $(74.3 \%)$ and temporal displacement $(74.3 \%)$ in equal measure as main coping strategies for crowding. $11.8 \%$ had explicitly chosen a cognitive coping strategy by taking high visitor numbers into account. A closer look at spatial displacement reveals that respondents largely preferred intra-area displacement (61.8\%) - they visited less frequented areas of the NP. The protected landscape Elbsandsteingebirge adjoining the NP was chosen as an alternative by only $9.2 \%$ of the respondents. Temporal displacement was mainly achieved by visiting the NP on another day of the week $(35.5 \%)$. Respondents also shifted their visit in terms of daytime (13.2\%) and season (25.6\%). 
The choice of coping strategy was highly dependent on the visitors' level of familiarity with the area. Firsttime visitors did not show any predominant strategy. They chose a different day of the week (35.5\%) and a shift in season $(29.0 \%)$ as well as intra-area displacement $(32.2 \%)$ in almost equal measure. In contrast, frequent visitors, who had visited the NP more than ten times, had a strong preference for intra-area displacement $(78.8 \%)$, because their mental map was much more detailed.

\section{Discussion}

\section{Crowding perception and its drivers}

The results of the level of crowding perception underline the unique position of the Bastei hotspot within the NP. Its social carrying capacity has been exceeded, with three of four visitors feeling at least moderately crowded. Slight forms of crowding, which occur at the other interview locations, are comparable to the results of Schreiner (2009), who investigated the eastern part of the NP.

The number of perceived encounters is the key factor for the perception of crowding. The correlation between encounters and crowding perception at the Bastei rock is comparable to the results of Graefe et al. (1984) who revised 16 crowding studies and found a medium correlation of 0.34 between encounters and crowding perception. However, if the whole western part of the NP is considered, the correlation is much higher, comparable to the maximum reported by Graefe et al. (1984).

The lower correlation at the Bastei, compared to the rest of the NP, may be influenced by the comparatively large area of the setting, but other factors may also contribute. Kuentzel et al. (2008) noted that visitors of popular destinations are much more flexible in the formulation of norms, resulting in a lower sensitivity to crowding and a toleration of higher visitor numbers. The displacement of crowding-sensitive visitors, in combination with a self-selection of visitors according to their preferences, and the influence of expectations, are possible explanations for this lower correlation. Furthermore, the Bastei attracts a large share of first-time visitors, a group which was found to be more tolerant to high visitor numbers (Graefe et al. 1984).

Even though the number of encounters seems to play a crucial role, other variables, such as motive for the trip and expectations, are also important. The finding that respondents who underestimated the number of visitors were more likely to report crowding is consistent with previous studies (Andereck \& Becker 1993; Lee \& Graefe 2003). The results of Webb \& Worchel (1993) indicate that, in the context of crowding, unconfirmed expectations change the evaluation of a setting. Respondents who expected a positive outcome and experienced a negative outcome evaluated the situation worse than those who had expected a negative outcome from the beginning.
Table 2 - Logistic regression with crowding perception as independent variable $(n=277)$. Included variables: behaviour, motive, familiarity, encounters, expectations, activity; ${ }^{a}$ ) Wald-test; Nagelkerke $\mathrm{R}^{2}=0.58$; correctly classified cases $=83.8 \% ; * 00.05$

\begin{tabular}{|c|c|c|c|c|}
\hline $\begin{array}{l}\text { Variable } \\
\text { (reference category) }\end{array}$ & $\begin{array}{l}\text { Regression } \\
\text { coefficient B }\end{array}$ & SE & Sig. ${ }^{a}$ & $\operatorname{Exp}(B)$ \\
\hline $\begin{array}{l}\text { Behaviour } \\
\text { (very positive) }\end{array}$ & & & .176 & \\
\hline Positive $(n=54)$ & -.431 & .499 & .387 & .650 \\
\hline Not positive $(n=56)$ & -.873 & .484 & .071 & .418 \\
\hline $\begin{array}{l}\text { Motivation } \\
\text { (nature experience) }\end{array}$ & & & .156 & \\
\hline Motivation recreation* $(n=38)$ & -1.620 & .739 & .028 & .198 \\
\hline $\begin{array}{l}\text { Activity with family and friends } \\
(\mathrm{n}=57)\end{array}$ & -.481 & .463 & .299 & .618 \\
\hline Other $(n=30)$ & -.56 & .639 & .476 & .634 \\
\hline \multicolumn{5}{|l|}{$\begin{array}{l}\text { Familiarity } \\
\text { (low familiarity) }\end{array}$} \\
\hline High familiarity $(n=174)$ & -.214 & .420 & .609 & .807 \\
\hline $\begin{array}{l}\text { Encounters } \\
\text { (few encounters) }\end{array}$ & & & .000 & \\
\hline Moderate encounters $(n=86)^{*}$ & 3.087 & .645 & .000 & 21.913 \\
\hline Many encounters $(n=60)^{*}$ & 4.985 & .733 & .000 & 146.175 \\
\hline $\begin{array}{l}\text { Expectations } \\
\text { (expectations met) }\end{array}$ & & & .270 & \\
\hline Overestimated $(n=81)$ & .287 & .480 & .550 & 1.332 \\
\hline Underestimated $(n=46)$ & .773 & .480 & .108 & 2.166 \\
\hline Activity & & & .042 & \\
\hline Going for a walk (n=52) & .397 & .495 & .423 & 1.487 \\
\hline Other $(n=9)^{*}$ & 2.786 & 1.143 & .015 & 16.224 \\
\hline Absolute term & -3.397 & .720 & .000 & .033 \\
\hline
\end{tabular}

Table 3 - Expectations of visitor numbers and crowding perception $(n=297)$. * Mann-Whitney-U Test $(p<0.01)$

\begin{tabular}{|l|r|r|r|}
\hline Expectations* & $\mathbf{N}$ & not crowded & crowded \\
\hline Heavily underestimated & 13 & $0 \%$ & $100 \%$ \\
Underestimated & 37 & $51.4 \%$ & $48.6 \%$ \\
Met & 157 & $70.1 \%$ & $29.9 \%$ \\
Overestimated & 84 & $82.1 \%$ & $17.9 \%$ \\
Heavily overestimated & 6 & $100 \%$ & $0 \%$ \\
Total & 297 & $68.7 \%$ & $31.3 \%$ \\
\hline
\end{tabular}

Table 4 - Strategies for coping with crowding $(n=311)$. * multiple answers allowed; percentage numbers refer to visitors who show or plan reactions to crowding

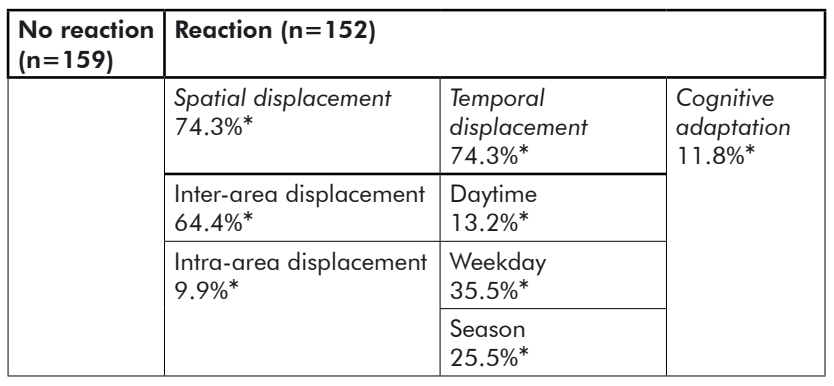

There is a second potential effect: visitors who underestimated crowding obviously had an incomplete information basis. They were not able to choose the sort of experience that best matched their preferences. In other words, visitors would have potentially avoided crowded places, as they are sensitive to crowding, but 
they could not because they didn't know the place was going to be crowded.

The perception of crowding also depends on the motive for the visit to the NP - different types of nature-based visitors to a NP have to be taken into account (Arnegger et al. 2010). Visitors who primarily want to experience nature are more sensitive to crowding than visitors with other motives. Crowding research has found similar results in different settings (Ditton et al. 1983; Manning 2011).

\section{Displacement effects and coping strategies}

About half of the visitors already reacted or plan to react to high visitor numbers. Other studies showed similar numbers, even though the situational variables differed greatly (Kuentzel \& Heberlein 1992; Hall \& Shelby 2000). In general the two major strategies, temporal and spatial displacement, were chosen in equal measure. However, visitors familiar with the area differ from the average visitor. They clearly prefer an intra-area displacement to any other form of displacement. They seem to find it easier than other visitors to use this coping strategy. They know the locality well, which helps them to find less frequented areas without having to invest resources to gain information (Arnberger \& Brandenburg 2007; Hall \& Shelby 2000). Nearly half of the visitors familiar with the area are overnight visitors and therefore their plans must include other factors like holiday times. This might be a reason why temporal displacement is not so popular in this group. Temporal displacement as a strategy may be also underrepresented in the survey as interviews were conducted in the peak season and at highly frequented times of the day.

\section{Conclusion and recommendations}

The results of the study indicate that crowding is already a widespread phenomenon at specific locations in the NP and that the perception of crowding mainly depends on the number of encounters but also on the expectations of use levels and the motive for the visit. Management measures against crowding should address these factors. As most tourists at the Bastei arrive by car, a more evenly distribution of the visitors across the day could be achieved by differentiated parking fees, with higher fees at the highly frequented times around midday. In addition, the NP management, in cooperation with local tourist stakeholders like the nearby thermal spa, should actively promote the advantages of visiting the Bastei off-season, for instance in winter. But this is only one element of an effective communication strategy as part of a good visitor management. The NP should inform visitors, especially first-time visitors, about the different recreational and natural experiences that they could expect in the different areas of the park. This would give visitors a clearer idea of the number of visitors to expect and enable them to plan their visit better in line with their preferences. This information has to be communicated effectively, i.e. readily accessible for the visitors and easy to understand.

The new mobile web technologies may open up many opportunities here. They enable visitors to obtain information at the point of demand, e.g. when they are affected by crowding and searching for alternatives. GPS-guided tours and educational geocaches can be used as innovative and interactive means of environmental education (Schrom-Feiertag et al. 2010) and at the same time help to manage especially natureinterested visitors by routing these tours through less frequented areas of the NP. In this way they can be an alternative for the ranger-guided tours, which can often only be booked in groups.

However, the true potential of this technology lies in inverting the direction of data transfer. Brown \& Weber (2011) used a public participation GIS to determine different recreational experiences in the NP system of Victoria, Australia. With GPS-enabled smartphones, gathering such data can become more intuitive for the visitors and cost-efficient for the NP management. Furthermore, it can be enriched by using the GPS-tracks of the route the visitors took through a certain area. Volunteered geographic information projects like OpenStreetMap show that there is a willingness to participate in such projects and that high levels of data quality can be reached.

\section{References}

Absher, J.D. \& R.G Lee 1981. Density as an incomplete cause of crowding in backcountry settings. Leisure Sciences 4 (3): 231-247.

Andereck, K.L. \& R. Becker 1993. Perceptions of carry-over crowding in recreation environments. Leisure Sciences 15 (4): 25-35.

Arnberger, A. \& C. Brandenburg 2007. Past Experience, Crowding Perceptions, and Use Displacement of Visitor Groups to a Peri-Urban National Park. Environmental Management 40 (2): 34-45.

Arnberger, A. \& C. Mann 2008. Crowding in European forests: a review of recent research and implications for forest management and policy. Forestry 81 (4): 559-571.

Arnberger, A. \& W. Haider 2005. Social effects on crowding preferences of urban forest visitors. Urban Forestry and Urban Greening 3: 125-136.

Arnberger, A. \& W. Haider 2007. Would You Displace? It Depends! A Multivariate Visual Approach to Intended Displacement from an Urban Forest Trail. Journal of Leisure Research 39 (2): 345-365.

Arnegger, J., M. Woltering \& H. Job 2010. Toward a product-based typology for nature-based tourism: a conceptual framework. Journal of Sustainable Tourism 18 (7): 915-928.

Brown, G. \& D. Weber 2011. Public Participation GIS: A new method for national park planning. Landscape and Urban Planning 102 (1): 1-15. 
Carothers, P., J.J. Vaske \& M.P. Donnelly 2001. Social Values versus Interpersonal Conflict among Hikers and Mountain Bikers. Leisure Sciences 23 (1): 47-61.

Ditton, R., A. Fedler, \& A. Graefe 1983. Factors contributing to perceptions of recreational crowding. Leisure Sciences 5: 273-288.

Graefe, A.R., J.J. Vaske \& F.R. Kuss 1984. Social carrying capacity: An integration and synthesis of twenty years of research. Leisure Sciences 6 (4): 395-431.

Grossmann, M., A. Klaphake \& J. Meyerhoff 2004. Canoes versus birds or canoeist versus canoeists? Combining interview survey and visitor monitoring to inform visitor management in Mueritz National Park. In: Sievänen,T., J. Erkkonen, J. Jokimäki, J. Saarinen, S. Tuulentie \& E. Virtanen (eds.), Policies, Methods and Tools for Visitor Management: 277-284. Rovaniemi.

Hall, T. \& J.W. Roggenbuck 2002. Response Format Effects in Questions about Norms: Implications for the Reliability and Validity of the Normative Approach. Leisure Sciences 24 (3/4): 325-337.

Hall, T. \& B. Shelby 2000. Temporal and Spatial Displacement: Evidence from A High-Use Reservoir and Alternate Sites. Journal of Leisure Research 32 (4): 435-456.

Hammer, T., I. Mose, T. Scheurer, D. Siegrist \& N. Weixlbaumer 2012. Societal research perspectives on protected areas in Europe. eco.mont 4 (1): 5-12.

Heberlein, T.A. \& J.J. Vaske 1977. Crowding and visitor conflict on the Bois Brule River. Madison.

Job, H. 2010. Welche Nationalparke braucht Deutschland?. Raumforschung und Raumordnung 68 (2): 75-90.

Job, H., M. Woltering \& C. Merlin 2010. Regionalwirtschaftliche Effekte des Tourismus im Nationalpark Sächsische Schweiz. In: Staatsbetrieb Sachsenforst (ed.), Der Nationalpark Sächsische Schweiz, als regionaler Wirtschaftsfaktor: 4-33. Bad Schandau.

Kalisch, D. 2012. Relevance of crowding effects in a coastal National Park in Germany: results from a case study on Hamburger Hallig. Journal of Coastal Conservation 16 (4): 531-541.

Kalisch, D. \& A. Klaphake 2007. Visitors' satisfaction and perception of crowding in a German National Park: a case study on the island of Hallig Hooge. Forest Snow and Landscape Research 81 (1/2): 109-122.

Kernen, R., M. Furrer, R. Rupf \& M. Wernli 2010. Visitor monitoring in the Protected Area Aletsch Forest In: Goosen, M., B. Elands \& R. van Marwijik (eds.), Recreation, tourism and nature in a changing world. Proceedings of the fifth international conference on Monitoring and Management of $V$ isitor flows in protected and recreational areas: 291-293. Wageningen.

Kuentzel, W.F., D. Laven, R.E. Manning \& W.A. Valliere 2008. When Do Normative Standards Matter Most? Understanding the Role of Norm Strength at Multiple National Park Settings. Leisure Sciences 30 (2): 127-142.

Kuentzel, W.F. \& T.A. Heberlein 1992. Cognitive and Behavioral Adoptions To Perceived Crowding: A
Panel Study of Coping and Displacement. Journal of Leisure Research 24 (4): 377-393.

Lee, H. \& A. Graefe 2003. Crowding at an arts festival: extending crowding models to the frontcountry. Tourism Management 24 (1): 1-11.

Manning, R.E. 2007. Parks and Carrying Capacity. Commons without Tragedy. Washington.

Manning, R.E. 2011. Studies in Outdoor Recreation. Search and Research for Satisfaction. Corvallis.

Manning, R.E. \& W.A. Freimund 2004. Use of Visual Research Methods to Measure Standards of Quality for Parks and Outdoor Recreation. Journal of Leisure Research 36 (4): 557-579.

Manning, R.E., W.A Valliere \& B. Wang 1999. Crowding Norms: Alternative Measurement Approaches. Leisure Sciences 21 (2): 97-115.

Manning, R.E., \& W.A. Valliere 2001. Coping in Outdoor Recreation: Causes and Consequences of Crowding and Conflict Among Community Residents. Journal of Leisure Research 33 (4): 410-426.

Mayer, M., M. Müller, M. Woltering, J. Arnegger \& H. Job. 2010. The economic impact of tourism in six German national parks. Landscape and Urban Planning 97 (2): 73-82.

Noe, F.P., W.E. Hammit \& R.D. Bixler 1997. Park User Perceptions of Resource and Use Impacts Under Varied Situations in Three National Parks. Journal of Environmental Management 49 (3): 323-336.

Schreiner, S. 2009. Visitor Management im Nationalpark Sächsische Schweiz: Verkehrsmanagement und Crowding-Forschung im Kirnitzschtal. Diploma-thesis (unpub.) Institute for Geography. Würzburg

Schrom-Feiertag, H., P. Luley, H. Stelzl, A. Almer, K. Taczanowska, C. Brandenburg, T. Hemma \& A. Muhar 2010. Informationsvermittlung, Besucheranalyse und nachhaltige Angebotsplanung in Schutzgebieten auf der Basis eines mobilen Guides. In: Egger, R. \& M. Jooss (eds.). mTourism. 183-194.

Shelby, B. 1980. Crowding models for backcountry recreation. Land Economics 56 (1): 43-55.

Shelby, B. \& T. Heberlein 1986. Carrying Capacity in Recreation Settings. Corvallis.

Staatsbetrieb Sachsenforst (ed.) 2011. Besucherkonzeption, Teil Wege. Available at: http:// www.nationalpark-saechsische-schweiz.de/red1/sachsens-nationalpark/rechtsgrundlagen/pageDB27781. html (accessed 17/12/2012)

Sterl, P., S. Wagner, A. Arnberger 2004. Social Carrying Capacity of Canoeists in Austria's Danube Floodplains National Park. In: Sievänen, T., J. Erkkonen, J. Jokimäkk, J. Saarinen, S. Tuulentie \& E. Virtanen (eds.), MMV Second: Policies, Methods and Tools for Visitor Management: 256-263. Rovaniemi.

Trachsel, A. \& N. Backhaus 2011. Perceptions and needs of older visitors in the Swiss National Park - a qualitative study of hiking tourists over 55. eco.mont 3 (1): 47-50.

Vaske, J.J., A. Graefe, B. Shelby \& T. Heberlein 1986. Backcountry encounter norms: Theory, method and 
empirical evidence. Journal of Leisure Research 18 (3): 137-153.

Vaske, J.J. \& M. Donnelly 2002. Generalizing the Encounter - Norm - Crowding Relationship. Leisure Science 24 (3/4): 255-269.

Vaske, J.J. \& B. Shelby 2008. Crowding as a Descriptive Indicator and an Evaluative Standard: Results from 30 Years of Research. Leisure Sciences 30 (2): 111126.

Volz, K.R. \& C. Mann 2006. Konfliktanalysen als Grundlage für die Entwicklung von umweltgerechten Managementstrategien in Erholungsgebieten. Eine Untersuchung zur sozialen Tragfähigkeit am Beispiel des Naturparks Schwarzwald Mitte/Nord. Freiburg im Breisgau.

Webb, W.M. \& S. Worchel 1993. Prior Experience and Expectation in the Context of Crowding. Journal of Personality and Social Psychology 65 (3): 512-521.

\section{Authors}

Johannes Schamel

(corresponding author), is research assistant at the Chair of Geography and Regional Science at the Julius-Maximilians-Universität, with a focus on visitor management in protected areas. Julius-MaximiliansUniversität Würzburg, Am Hubland, 97074 Würzburg, Germany. Email: johannes.schamel@uni-wuerz burg.de

Hubert Job

holds the Chair of Geography and Regional Science at Julius-Maximilians-Universität Würzburg. His research focuses on protected areas from an economic and social perspective. Julius-Maximilians-Universität Würzburg, Am Hubland, 97074 Würzburg, Germany. 